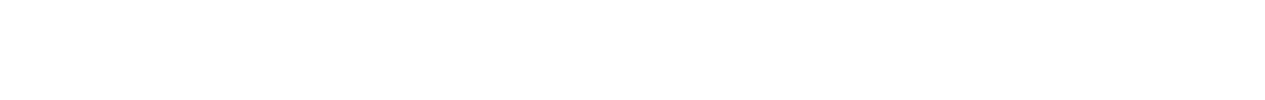 نكور الجرذلن البيض
}

\author{
مف مسبن جانكير \\ قصم علوم الحية \\ كلية العلوم عالو \\ جلمعة الموصل
}

E. mail: munahj04aa@yahoo.com

(تاريخ الاستلام 5/ 10 /2011 ؛ تاريخ القبول 26 /12 / 2011)

\section{الملغص}

تضمنت الدرلسة الحالية معرفة تأثير الرصاص على بعض مضادات الإكسة الاذزيمية وغير الانزيمية

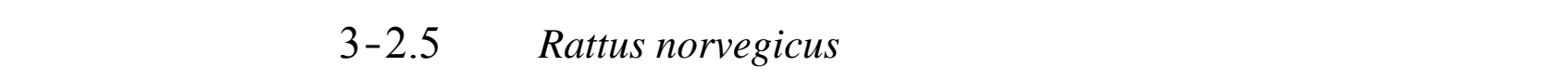

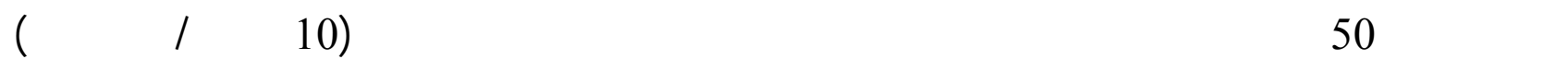

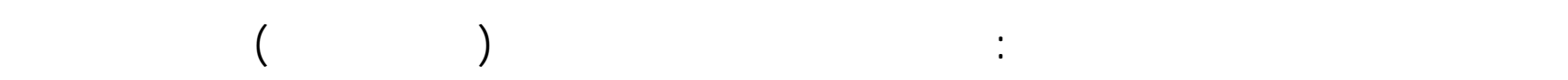

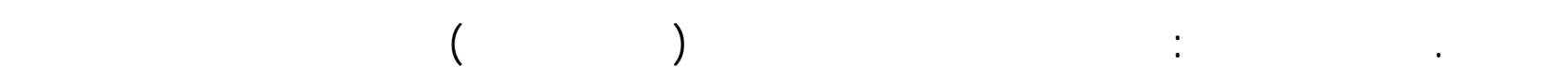

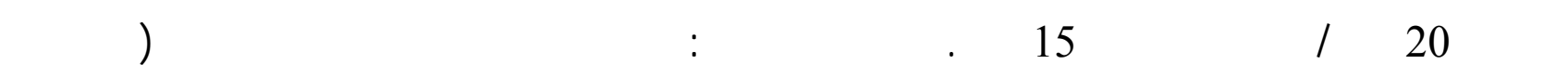

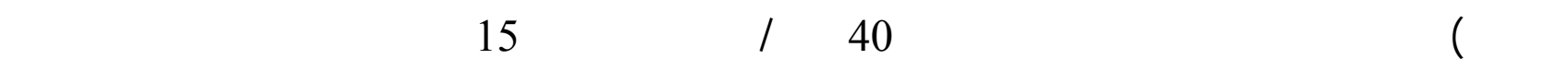

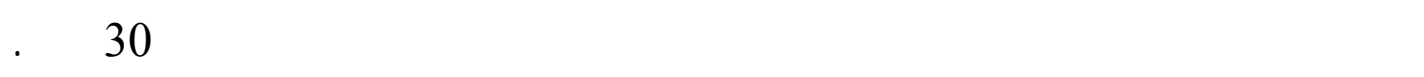
لظهرت نتائج المعلملة بالرصاص انغضاضا معنويا في تركيز كل مـ ن الب ـروتين الكل ي والالب -ومين

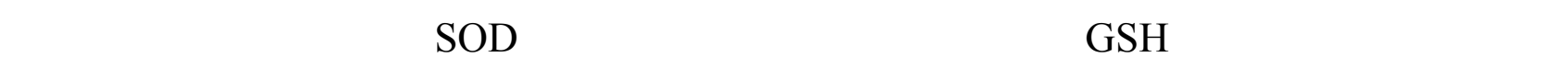

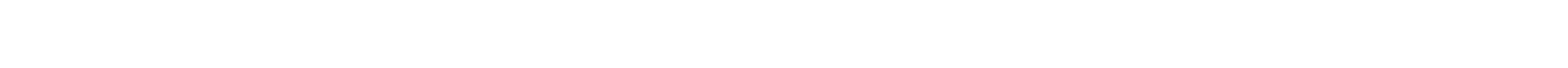

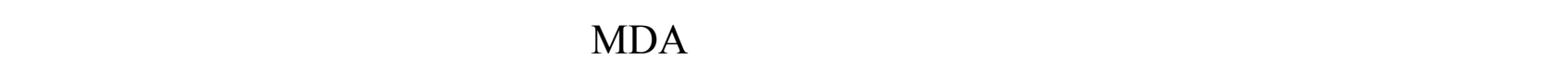
مجموعة للسطرة، كما اوضحت النتائج ان الانخفاض والارتفاع لكثر وضوحا في مجموعة الجرذان المعلملة

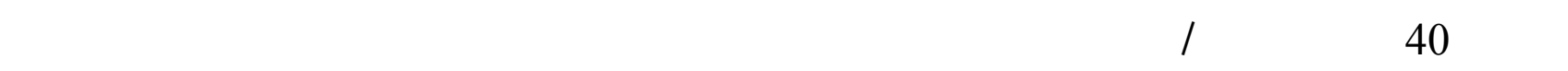

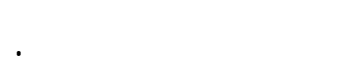

الكاملت الدالة: الرصاص، الكلوتاثايون، المالوندايالديهايد، حلمض اليوريك،سوبر اوكسايد هسميوتيز. 
من عسبن جانكير

\title{
Effect of Lead on some Antioxidants and Lipid Peroxidation in Blood of White Male Albino Rats
}

\author{
Muna H. Jankeer \\ Department of Biology \\ College of Science \\ University of Mosul \\ E-mail: munahj04aa@yahoo.com
}

\begin{abstract}
The present study includes the investigation of the effect of lead on some enzymatic, non enzymatic antioxidants and lipid peroxidation in serum of male albino rats Rattus norvegicus aged 2.5-3 months. Fifty male rats were randomly divided into 5 groups (10 rats/ group).The first group: was given standard forage and distilled water (as a drinking water) and considered as control. The second group: was given standard forage and distilled water (as a drinking water) containing $20 \mathrm{mg}$ lead /L. daily for a period of 15 days. Third group: was given standard forage and distilled water (as a drinking water) containing $40 \mathrm{mg}$ lead/ L. daily for a period of 15 days. The fourth and fifth groups were treated with the same concentration of the second and third group separately daily for a period of 30 days.

The results showed that treatment with lead caused a significant decrease in the concentration of each of total protein, albumin, globulin, glutathione GSH and the superoxide dismutase SOD activity in serum of treated rats compared with the control group. The reduction of the above mentioned parameters was progressive with the time of treatment. The result also showed that treatment with lead caused a significant increase in uric acid and malondialdhyde MDA in serum compared with control group. The results also showed that the decrease and increase were more prominent in rats treated with $40 \mathrm{mg}$ lead/ L of drinking water. These results suggests that lead may induce oxidative stress in albino rats.
\end{abstract}

Keywords: Lead. Glutathione, Malondialdhyde, Uric acid, Superoxide dismutase.

\section{المقمة}

يعد الرصاص لحد المعان القيلة الملمة، يتولجد في الطبيعة بصورة غير قية مرتبا بخلملت لخرى

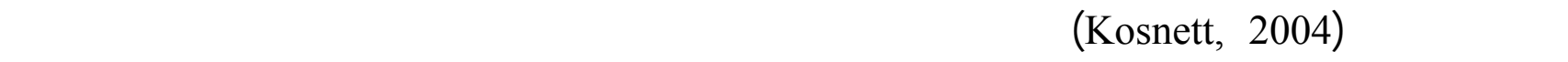

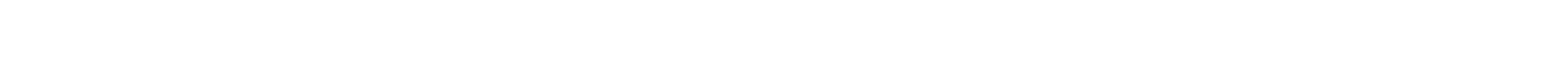

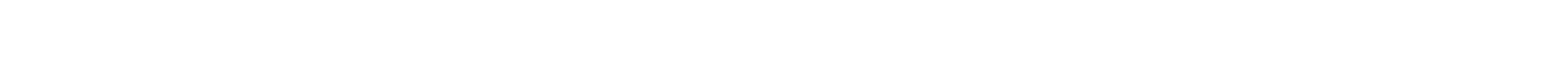

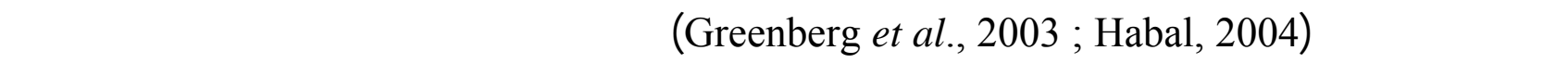

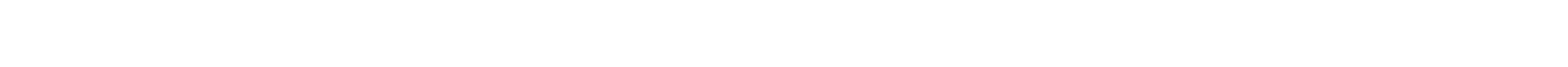


والزجاج ومعلبت حنظ الاغنية (ATSDR, 2005 ; Jankeer and EL-Nouri, 2009)، لذا تؤدي مخلف لت

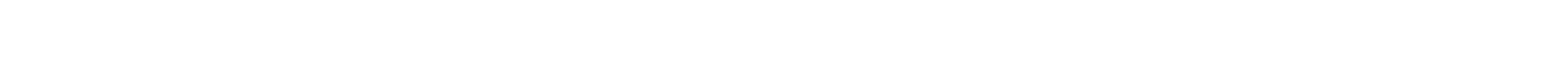

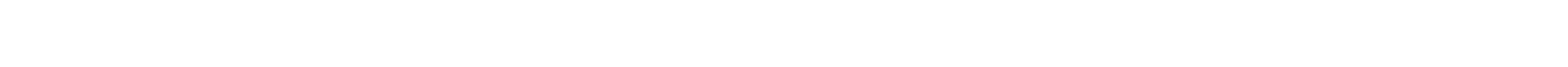
الغذائية الإسلسية للإنسان (للسيد، 2000 ؛ الجبوري، 2006)، وتكمن خطورة الرصاص في كوذ هـ يمتل لـك

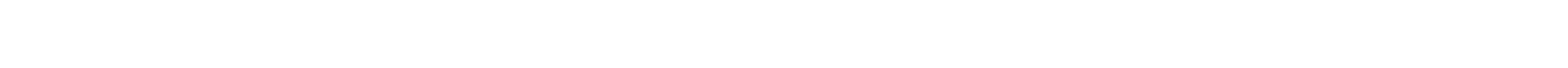

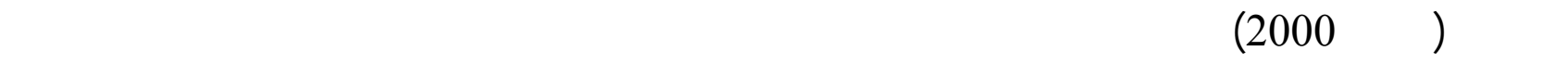

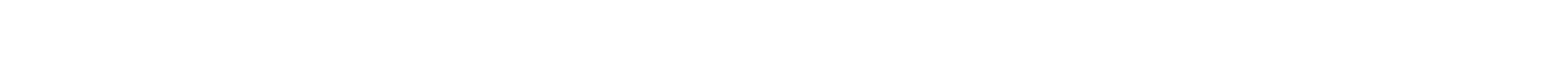
والطحل والنماغ (Plumlee, 2004 ; Mudipalli, 2007). ان الكرب الذي تسبه المعان القيلة Heavy metals stress مل الرصاص ومركباته ينهم عنه التتاج

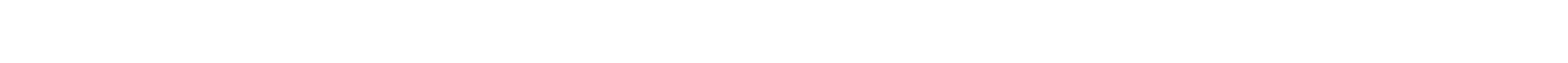

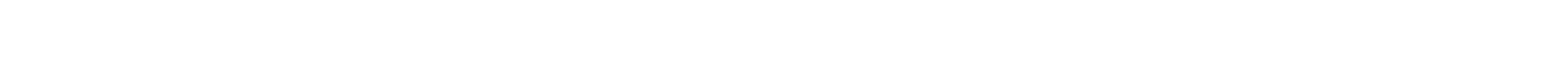
المققة (Hermes-Lima et al., 1991; Choudhury and Panda, 2004). ويمكن لستحداث حالات الكرب التلكسدي بوسطة بعض المباض المع الن القيل سة كالرص اص، ف التعرض للارصاص ومركباته له علاقة وثيقة مع الكرب التلكسدي والجذور الحرة في الجسم ( ;

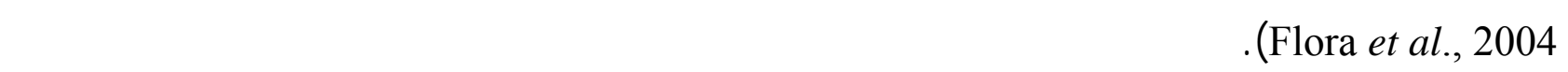

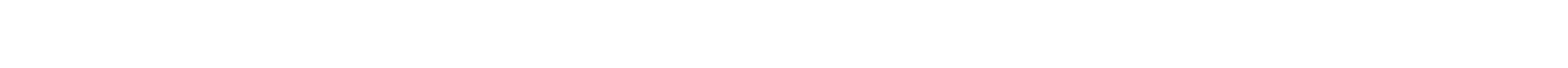

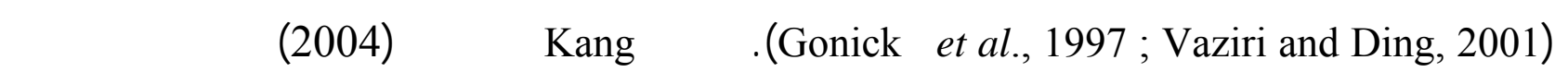
الانزيمكت الضرورية التي تعدموادًَ مانعة للأكسدة مل انزيم فوس فولبيد هايدروبيروك سيديز كلوتاث ايون بيروكسيديز Phospholipid hydroperoxidase Glutathione peroxidase (PHGP) في أمغية الجروذان المعرضة للرصاص. إن التعرض للرصاص والتسمم بمركباته يسب تغيرًَ في مضاد الإنسة غير الانزيمي

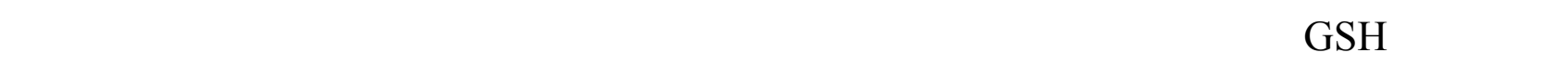
الغشاء الخلوي للسوالز (El-Sokkary et al., 2003). بينت العديد من الدرلسك بلن الرصاص يحدث الكرب التلكسدي من خلل عدة أليات:

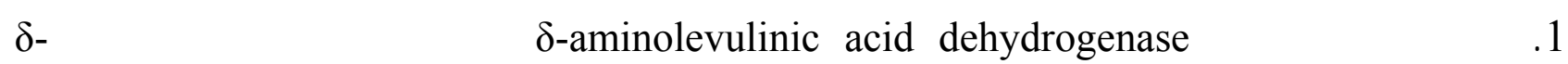

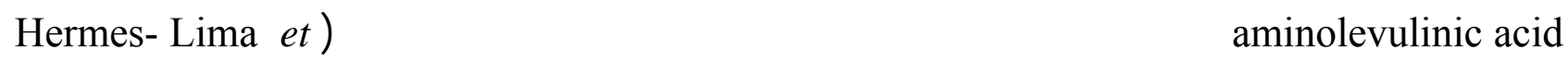
.(al., 1991 ; Sandhir et al., 1994

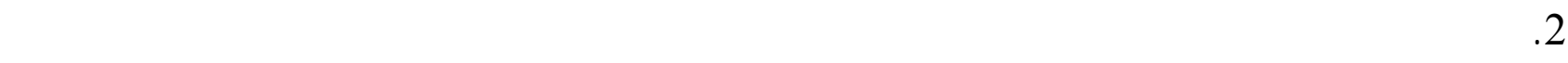
.(Donaldson and Knowles, 1993) 
3. يرتبط الرصاص مبلثرة مع الاغثية الخلوية حل وصوله للخلايا مؤيا إلى حدوث بيروكسدة الدهن .(Quinlan et al., 1988) 4. ارفاع في مستويت الكللسيوم دلخل الخلية وتمير وظيفة المايتوكوندريا (بيوت الطاقة)، (الجبوري، . (2006 5. لمتتفاذ مضادات الأكسة غير الاززيمية، مما يضعف قدرة الخلايا على مقاومة التلكسد وكلها بالنتيجة تؤدي اله تلف الخلايا وتكوين الكرب التلكسدي (Demir et al., 2003).

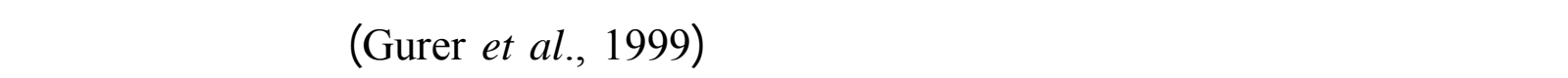

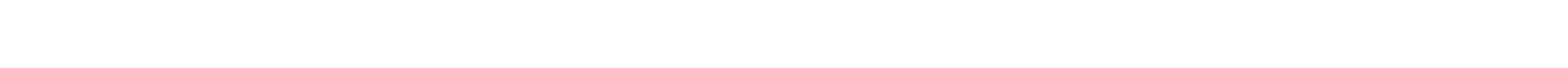
نكور الجرذان البيض وقصي مدى انعكلس ذلك على الانسلن عند التعرض اللسمو المشابه لها بيئيا ومهنيا.

\section{المواد ولرائق الهلل}

الحيولنا المستخمة

تهيئة الحيولنت

لستخدت في الدرلسة الحالية 50 من نكور الجرذان البيض Rattus norvegicus بعمر 2.5 -3 لشثهر

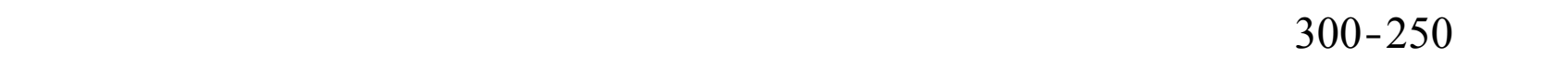

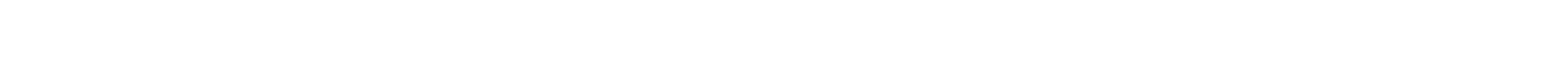

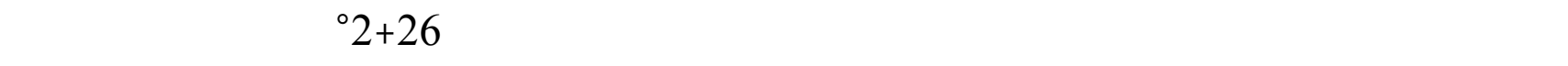

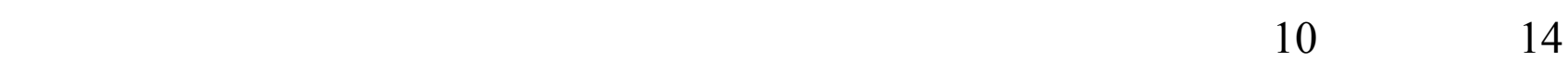
على المكلن، وغذيت الحيوانتا على العلقة المركزة المحضرة وفقا للمظلبلت التغذوية والفسلجية التي أُرها

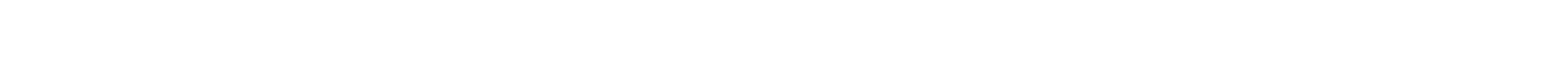

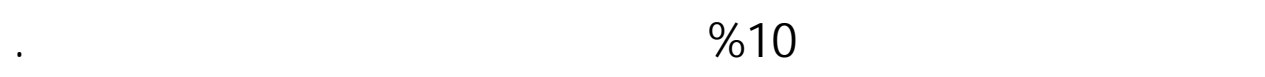

\section{تصميم التجارب}

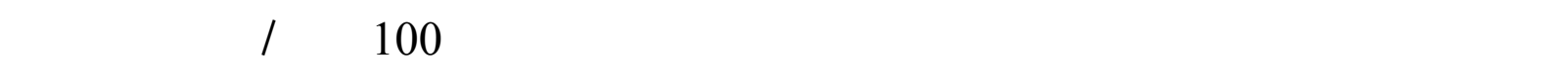

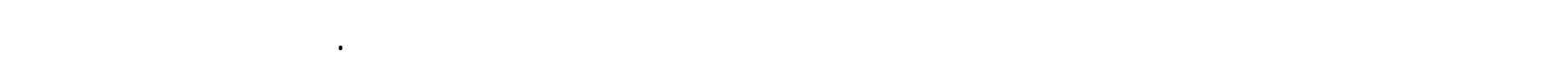

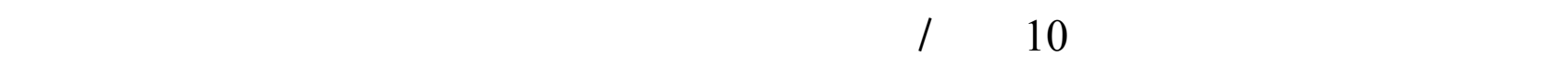
النحو الاتي: 1. مجموعة اللسيلرة: م معلملة هذه المجموعة بإعائها عليقة قيلسية مع ماء متطر (لغرض الثرب) في قنان حجميةسعة نصف لتر وبحهم 200سم / يوم. 
2. المجموعة المعاملة بخلات الرصاd بتركيز20ملفم/ لتر: قم معلملة هذه المجموعة بإعائها علق مة

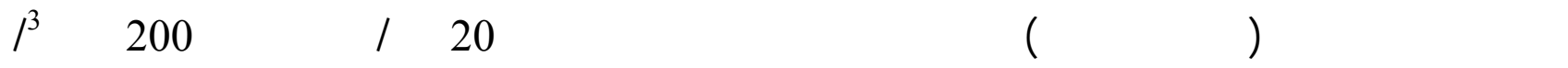
يوم ولمدة 15 يوما.

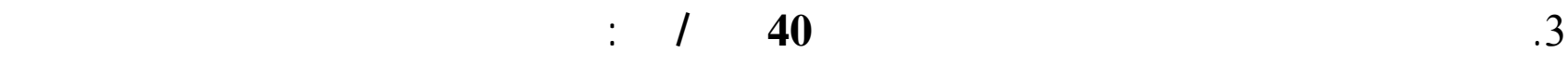

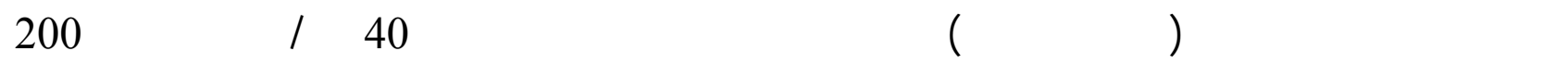
سم "/لوم ولمدة 15 يوم. لما المجموعة الرلبعة والخلمة عوملت بخلات الرصاص بتركيز 20 ملغم و40 ملغم / لتركلّ عله الفراد ولكن لمة 30 يوما (Moussa and Bashandy, 2008).

\section{جمع وحظا العينات:}

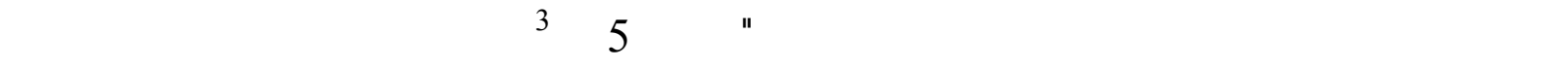

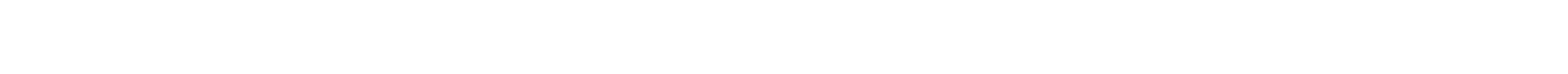

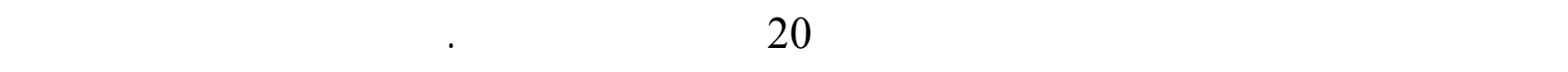

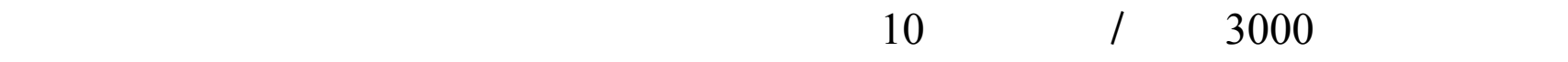
المختلفة (Tietz, 1999).

\section{قدير تركيز بيروكسة الدن في مطل الع:}

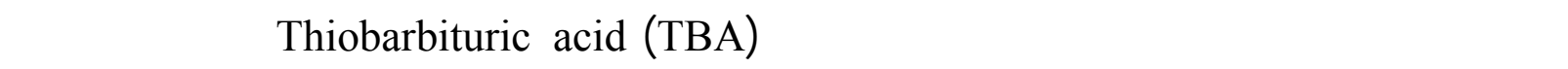

المالوندايالديهايد Beuge and Aust , 1978) MDA).

\section{فحير تركيزمضاكل الاكسة غير الانزيمية ولانزيمية في مطل الهم:}

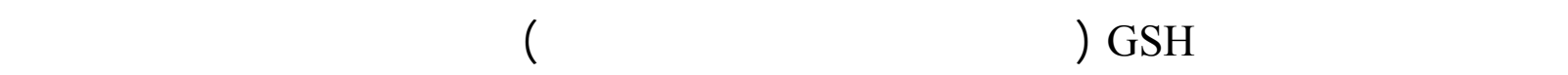

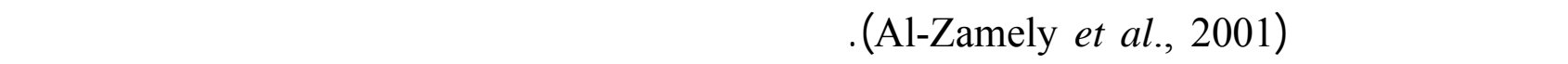
(Gornall et al., 1949)

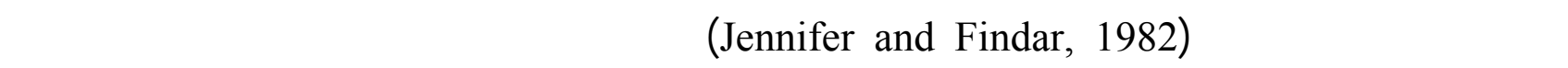
Biolabo المعادلة الاتية (Tietz, 1999) .

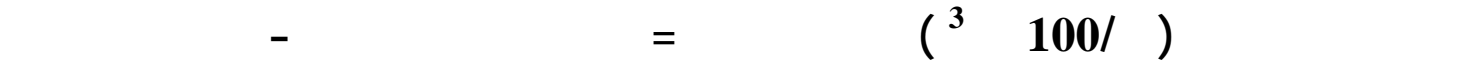

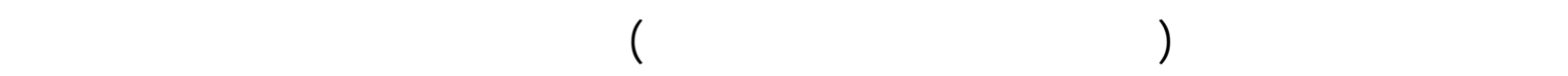
Biolabo سوبر اوكسايد هسيموتيزSOD (بوصفه مضاد لمسدة أنزيمي) في مطل الدم بلستخدلم الطريقة المحورة مه ن قبل (Brown and Goldstien, 1983). 


\section{الحلالل الإحصائي}

فذت تجربة علملية بلستخدم التصميم العشوائي الكلمل، وحللت النتائج لحصائيا، ولستخدم لختبار ننكن

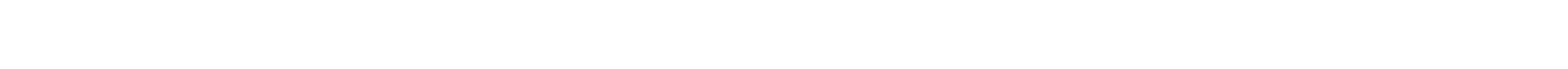
معنوية عند مستوى لحتمل (P<0.05).

\section{النتائج والمنالشة}

يبين الشكل (1) ان معلملة الجرذان بتركيز20 و40ملغم رصاص/ لترمن ماء اللثرب بع ده مـ -رور

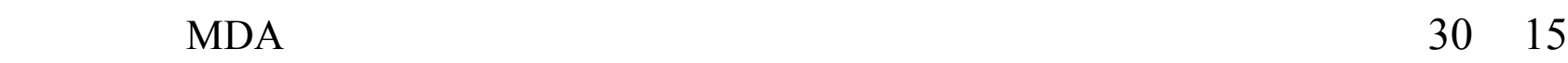

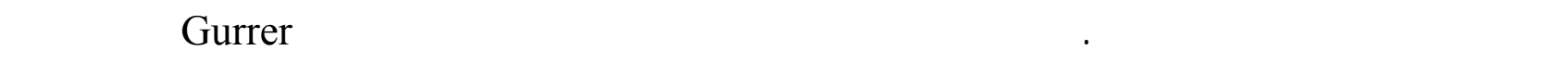

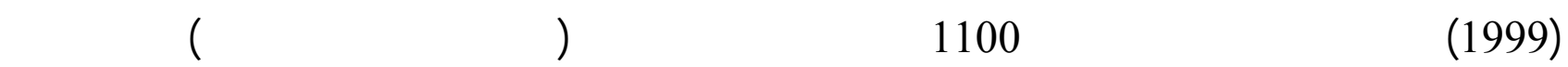

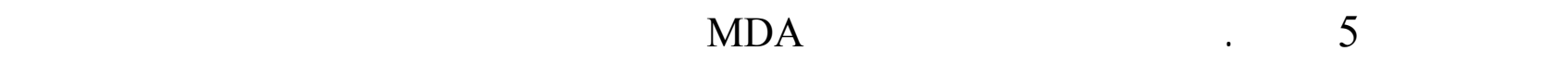

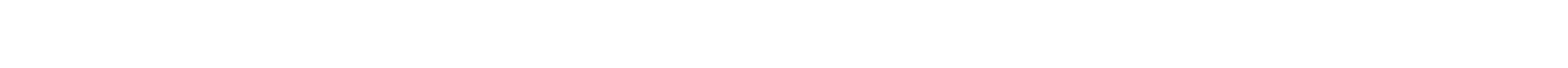
MDA لحد النواتج النهائية لعملية بيروكسدة الدهن. كما ألشارت العديد من الدرلسك إلى ان الكرب التلكسدي الذي يسببه الرصاص في الانسجة المختلفة

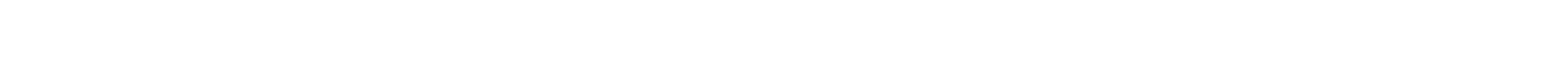
الصنف الاوكسجين الفعالة (Taki et al., 1985 ; Gurrer et al., 1999) وبين المل من ( Monterio et al., 1986 ; Monterio et al., 1989 ان التسم بالرصاص يؤدي اله تحرر الصنف الاوكسجين الفعال لمة مث لل

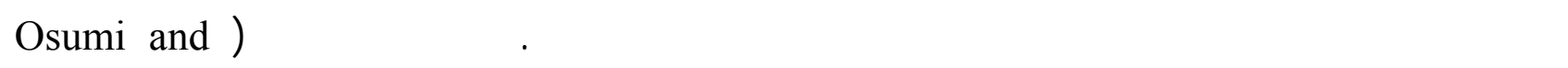
(Hashimoto, 1978 ; Basha and Sovers, 1996 Fatty-acyl-CoA oxidase الدلخلي المنشأ والذي يسهم في أنتاج بيروكسة الدهن (Donaldson and Knowles, 1993). 


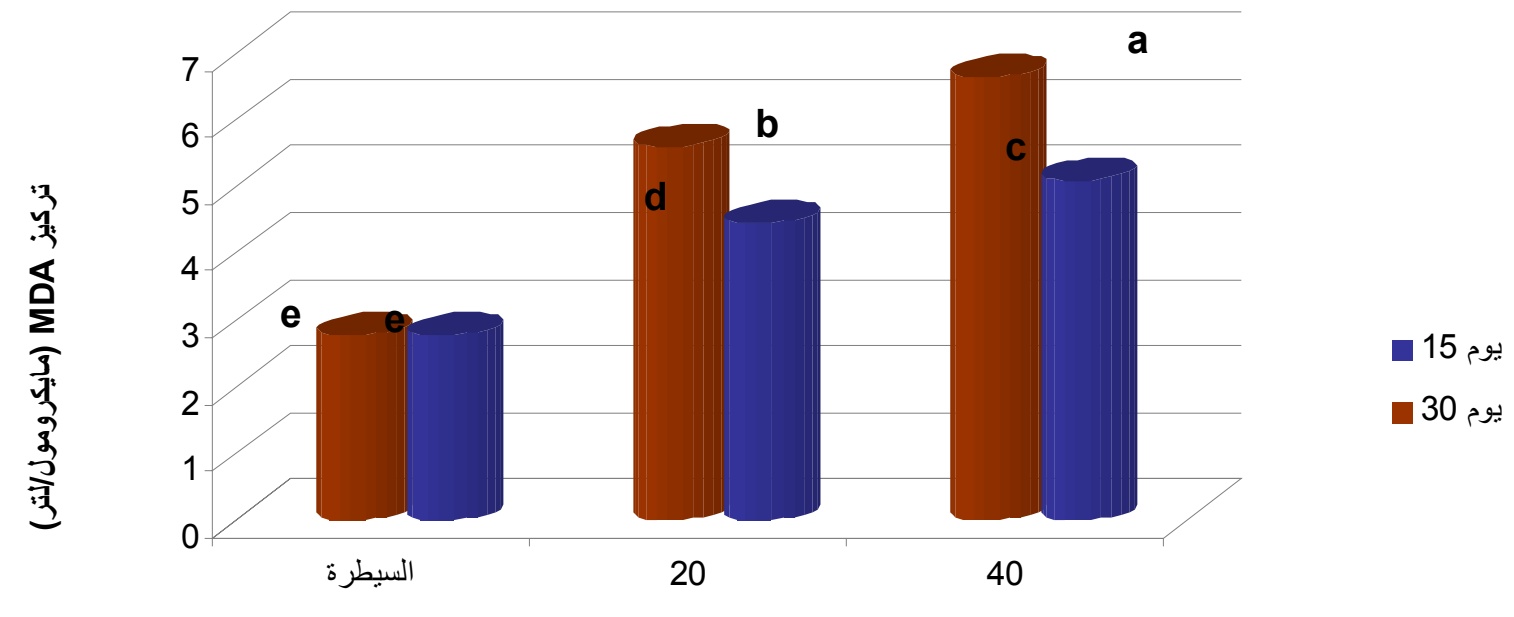

تركيز الرصاص (ملفم/لتر ماء شرب)

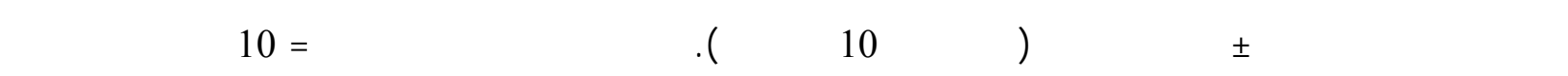

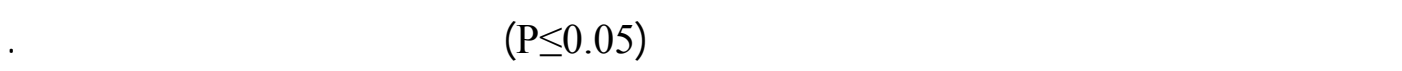

الثشل 1: تأثير الرصاص في تركيز المالوندايالديهايد MDA في مصل م نكور الجرذان المعلملة بتركيز

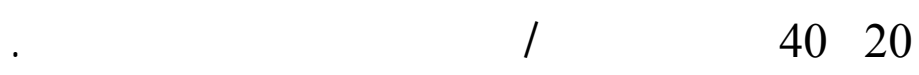

كما أدت معلملة الجرذان بكلا التركيزين 20 و 40ملغم رصاص / لترمن م اء الـ شرب واففت _رات

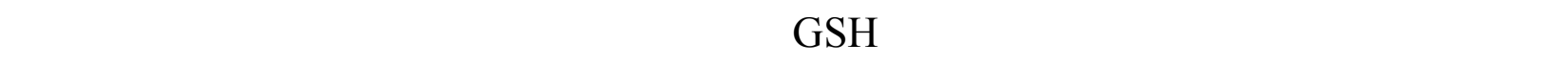

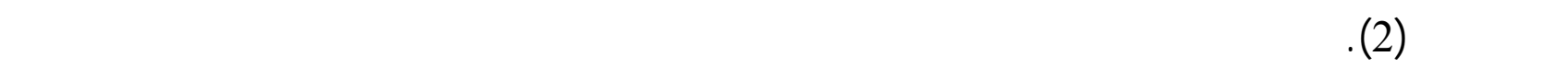
(Prasada Rao et al., 1983 ; Sandhir et al., 1994 ; Bagchi et al., 1996 ; Gurrer et al., 1999)

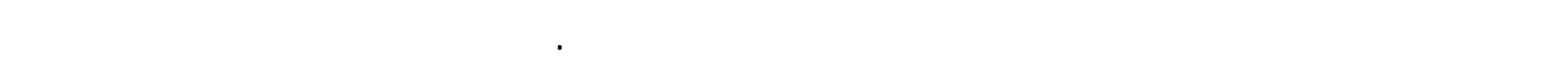

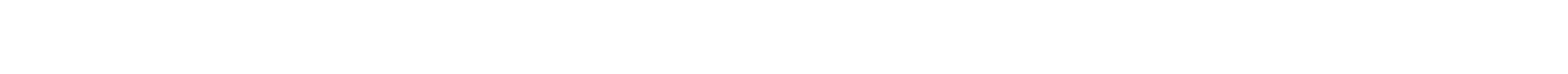

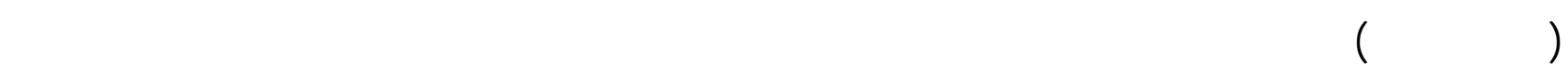

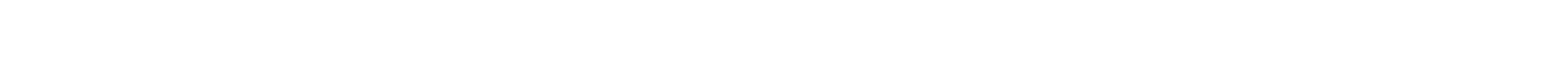

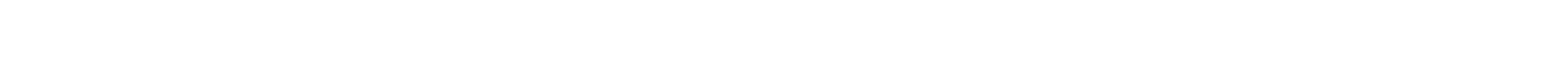

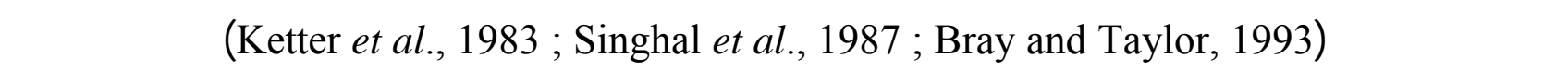
GSH اله أن النخفاض ترلكي -ز الكلوتاث ايون المخت _زل (Sandhir et al., 1994 ; Gurrer et al., 1999)

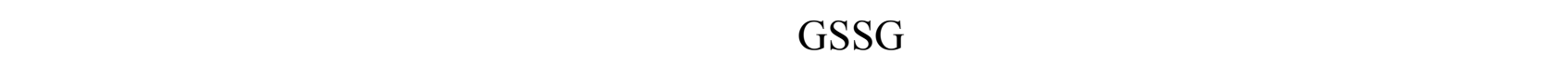
فمن المعروف ان الرصاص يسب الاذى التلكسدي متمثلة بيروكسة الدهن في الاغثية الخلوية. 


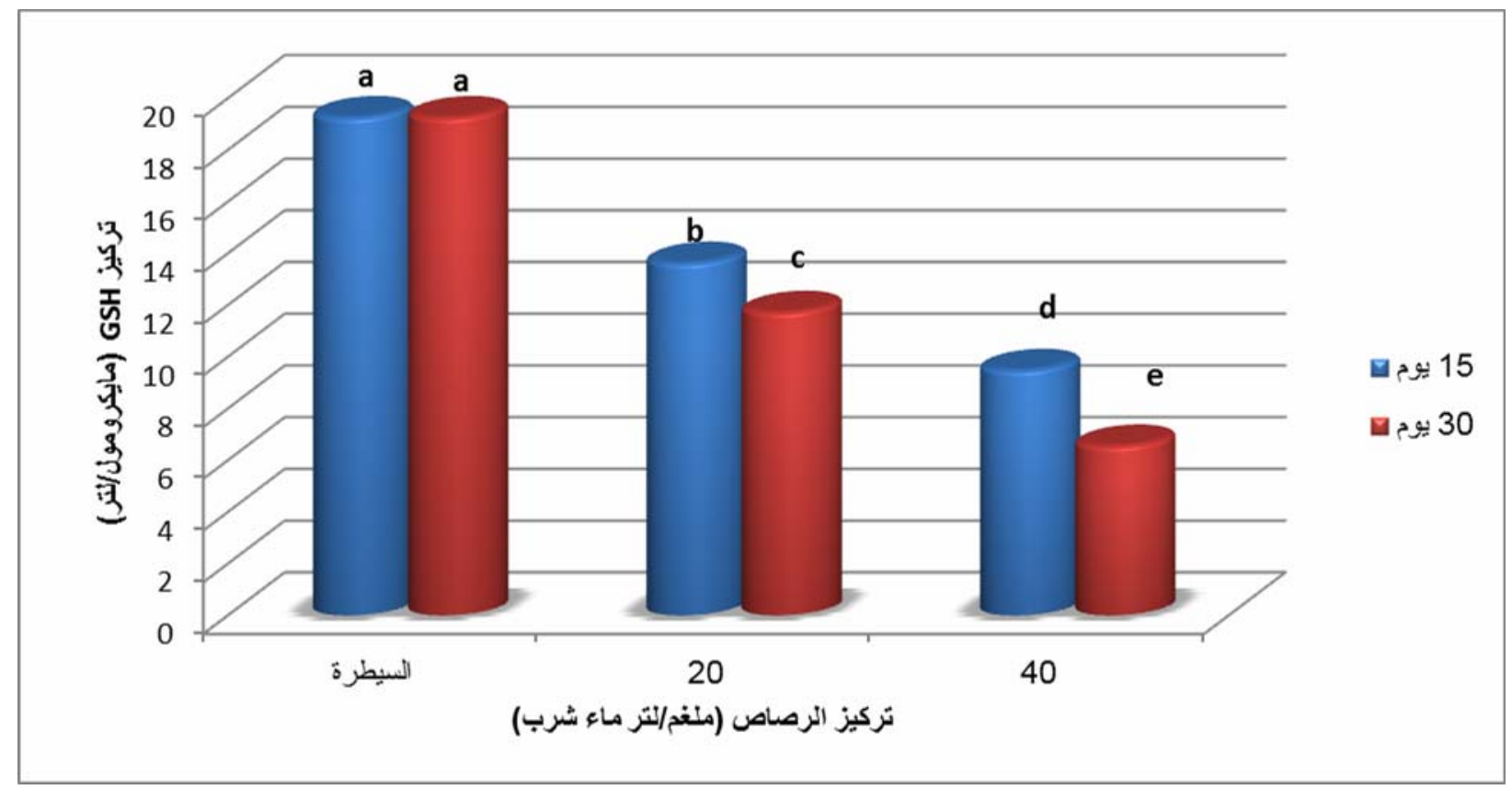

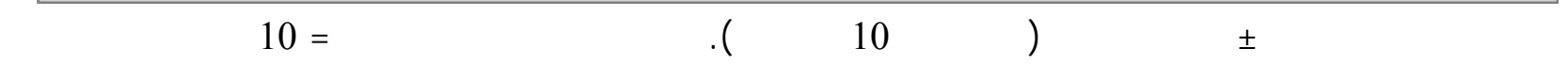

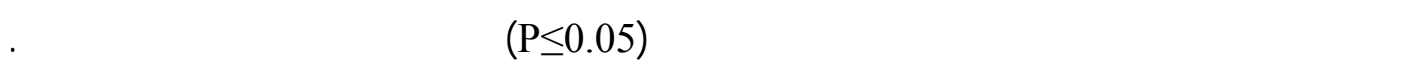

للثكل : تأثير الرصاص في تركيز الكلوتاثايون GSH في مصل هم نكور الجرذان المعلملة بتركيز 20 و40ملغم رصاص / لتر ماء الثدرب وافترات مختلفة .

لظهرت النتائج في للشكل (A.3، B.3، أن معلملة الجرذان بارصصاص لكلا التركي -زين م ع م Lاء للثرب أدت إلى حدوث لنغفاض معنوي في تركيز كل من البروتين الكلي والالبومين والكلوبيولين في مصل الدم مقارئة مع مجموعة للسطرة. تقفق هذه النتائج مع ما توصل إليه لكل من ( جانكير، 2010 ؛ :

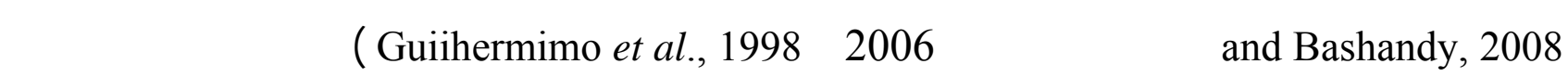
لكل من عنصر الرصاص والكاسميوم على تركيز البروتين الكلي والالبومين في مصل دم الجرذان والفئران.

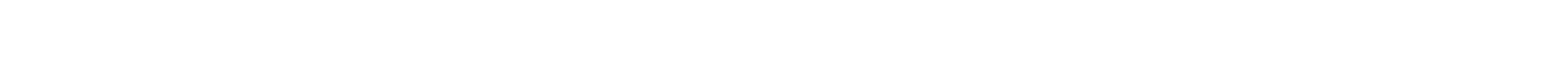
الاوكسجين الفعالة، كما يعود ذلك اله الكرب التلكسدي المحدث بالرصاص، لـ ذذك يت ـضح دور الالب -ومين

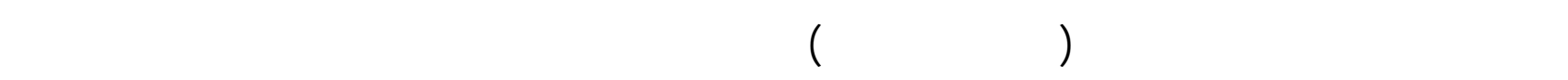
الحرة وذل لك بك سررسل سلة الق اعلات واء الة الص سلاح الجزيئ لت الحيوي ـة المت صضررة تلك سيا

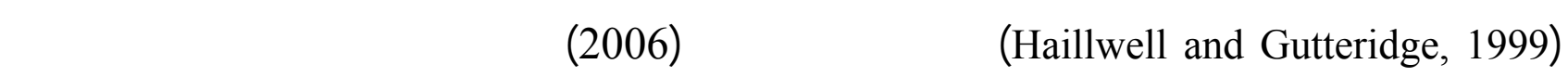
البروتين والالبومين والكلوبيولين في الفئرن المعلملة بالرصاص هو تهطم وتحل البروتينات لستجابة لتأثير

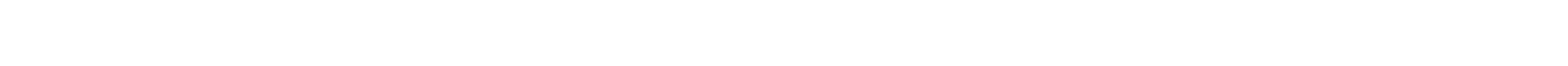
تكوين بعض الاحماض المينية ال لـرورية لبن اء البروتيذ لت .كم الث ار(Tang and Enger, 1994) 
إلى أن التسم بالرصاص يؤدي اله حدوث خل في اليض الحلمض النووي الرايبوزي المقوص الاوكسجين

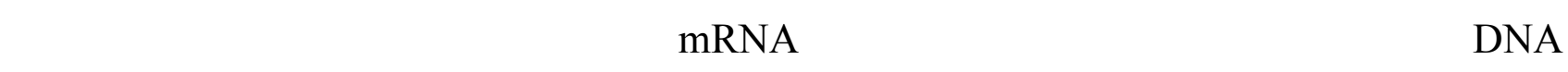
في الكبد، لذا فلن التأثير للسلم للرصاص في الدم يبدو واضضحا من خلل النخفاض تركيز البروتينات الكلية في

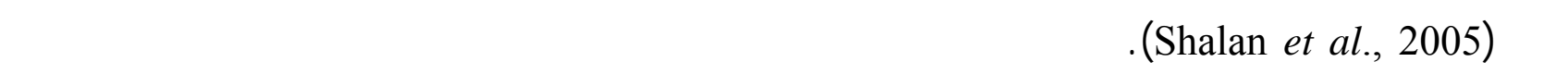

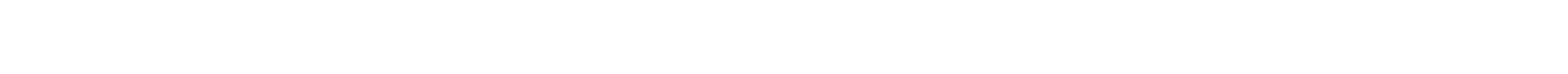

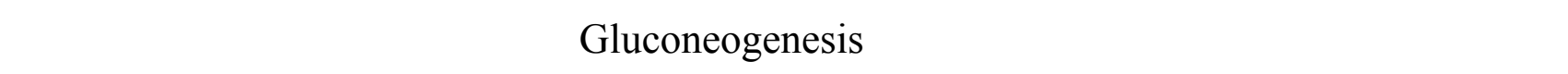
كاربوهيدراتية (William, 1984 ; Freeman, 1988).

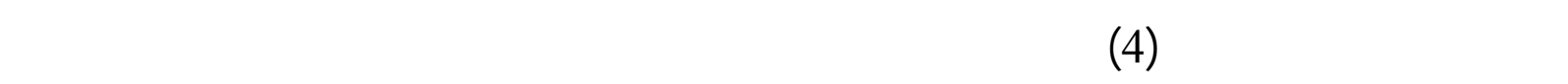

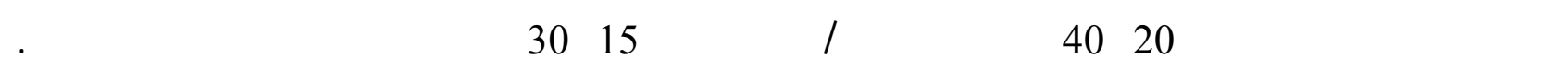

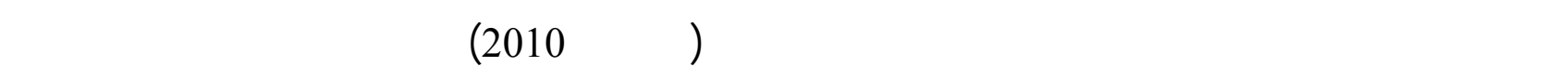

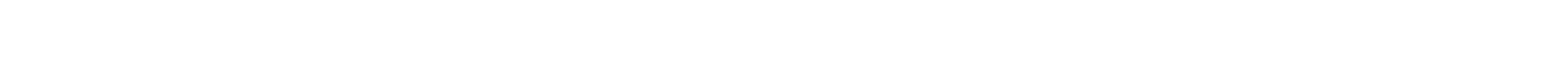

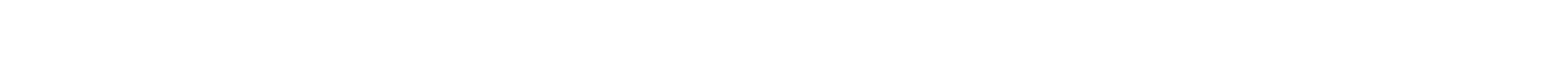

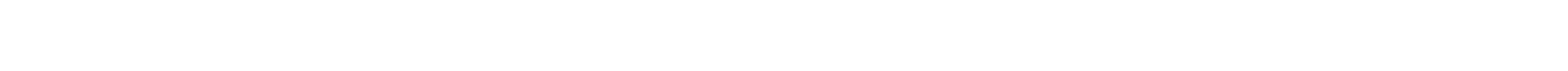

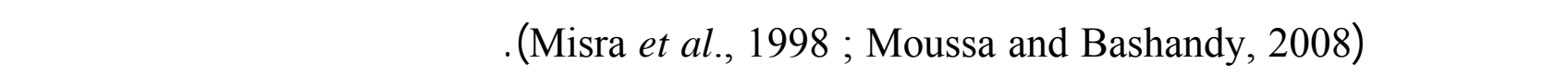

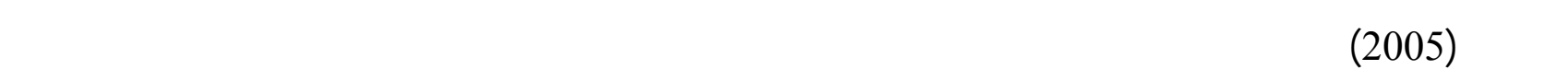

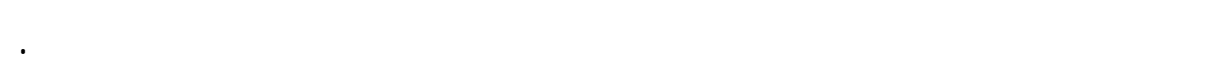




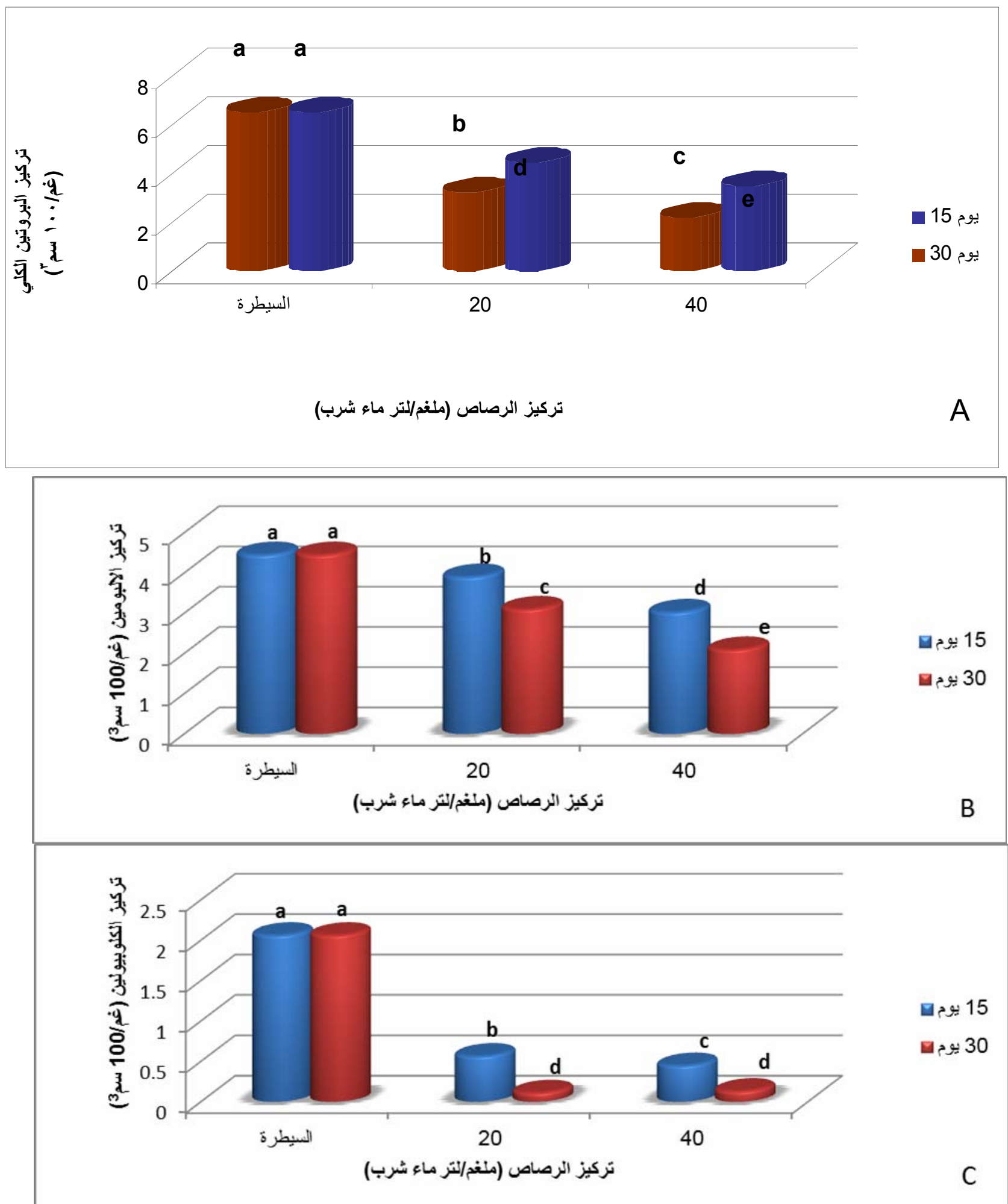

القيم معبر عنها بالمعلل

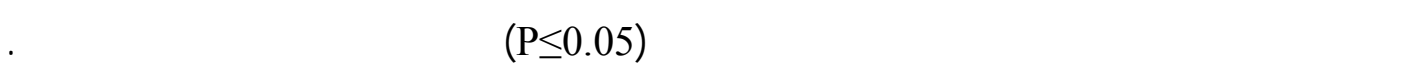




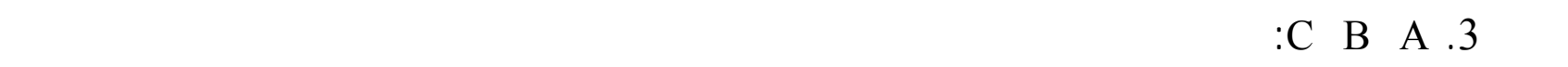

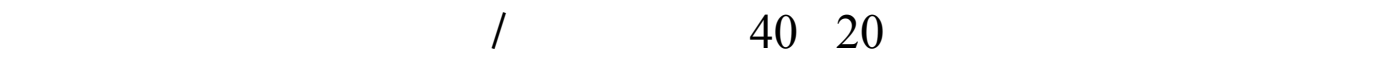

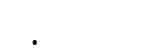

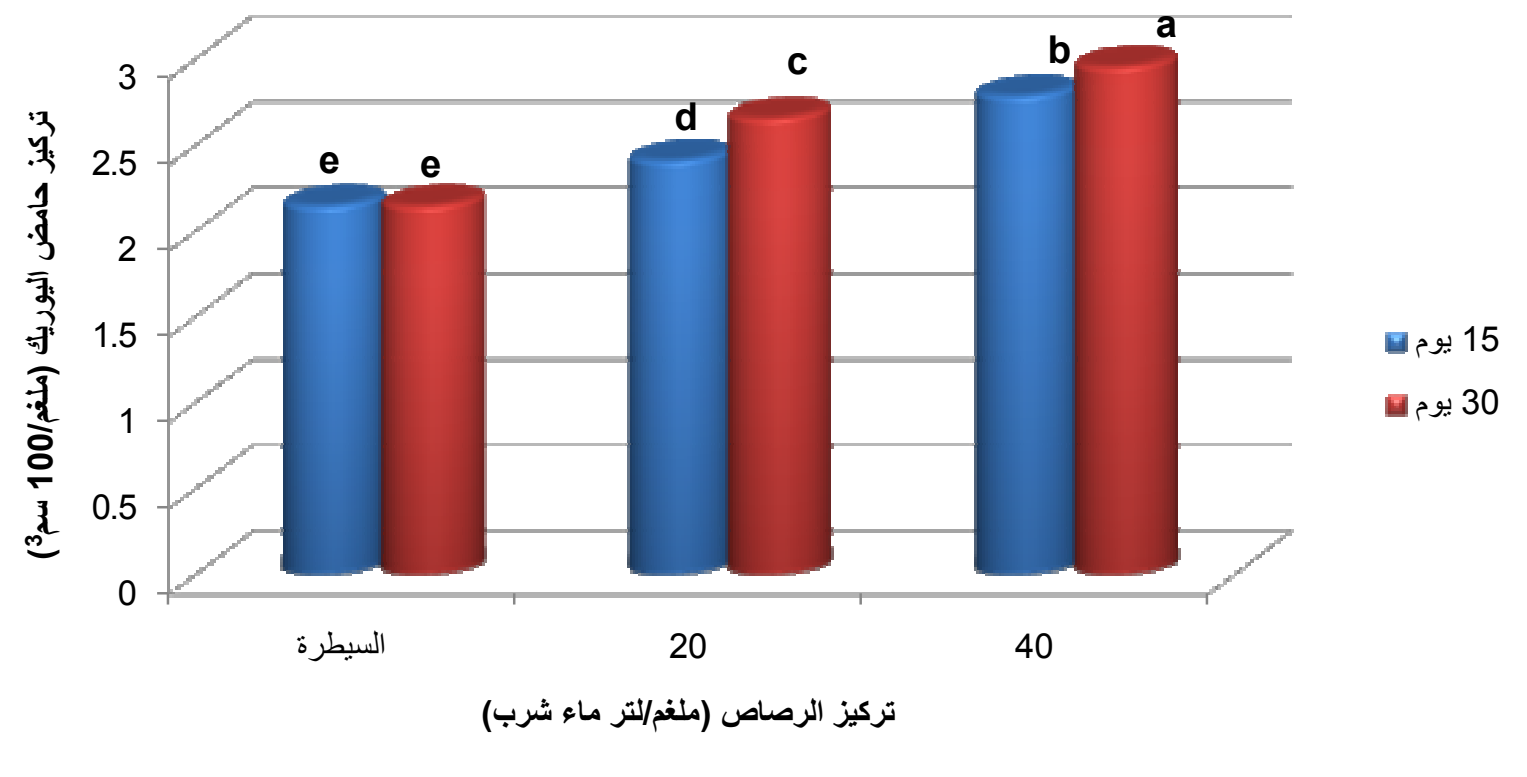

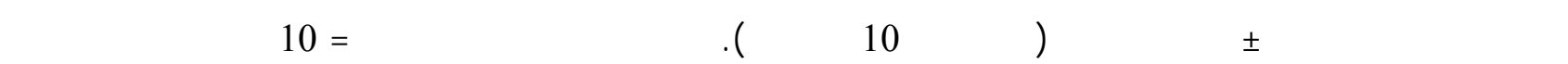

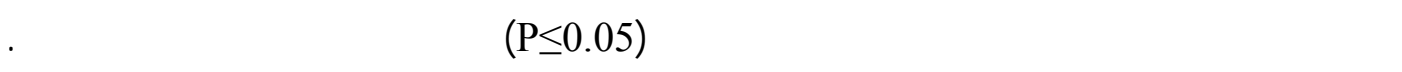

الشكل 4: تأثير الرصاص في تركيز حلمض اليوريك في مصل هم نكور الجرذان المعلملة بتركيز 20 و40 ملغم رصاص / لترماء اللثرب ولفترات مختلفة.

أوضحت نتائج اللشكل (5) انخفاضا معنويا في مستوى التغير في لمتصاصية الفورمازين لفعالية اذ ززيم

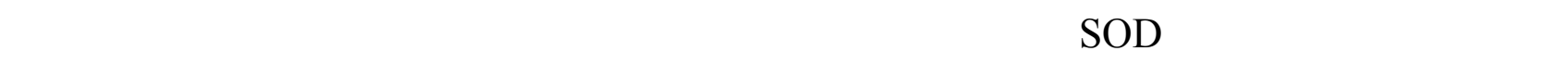

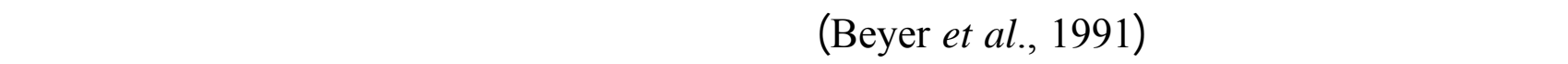

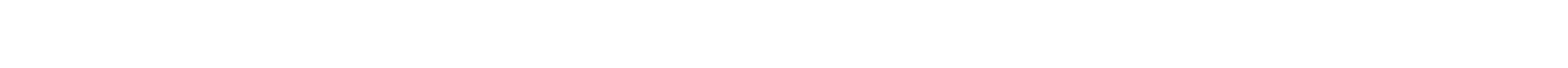

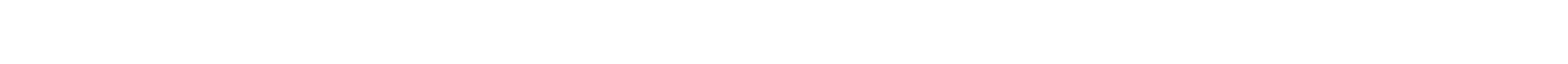

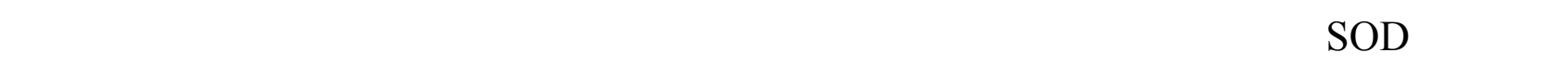
الغزيم الكاتاليز (Guemouri et al., 1991 ; Sies, 1997).

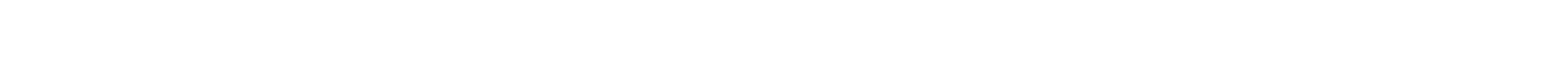
عضو في الجبم ويحدث خللا في العنيدمن العمليت الفسلجية والايضية. 


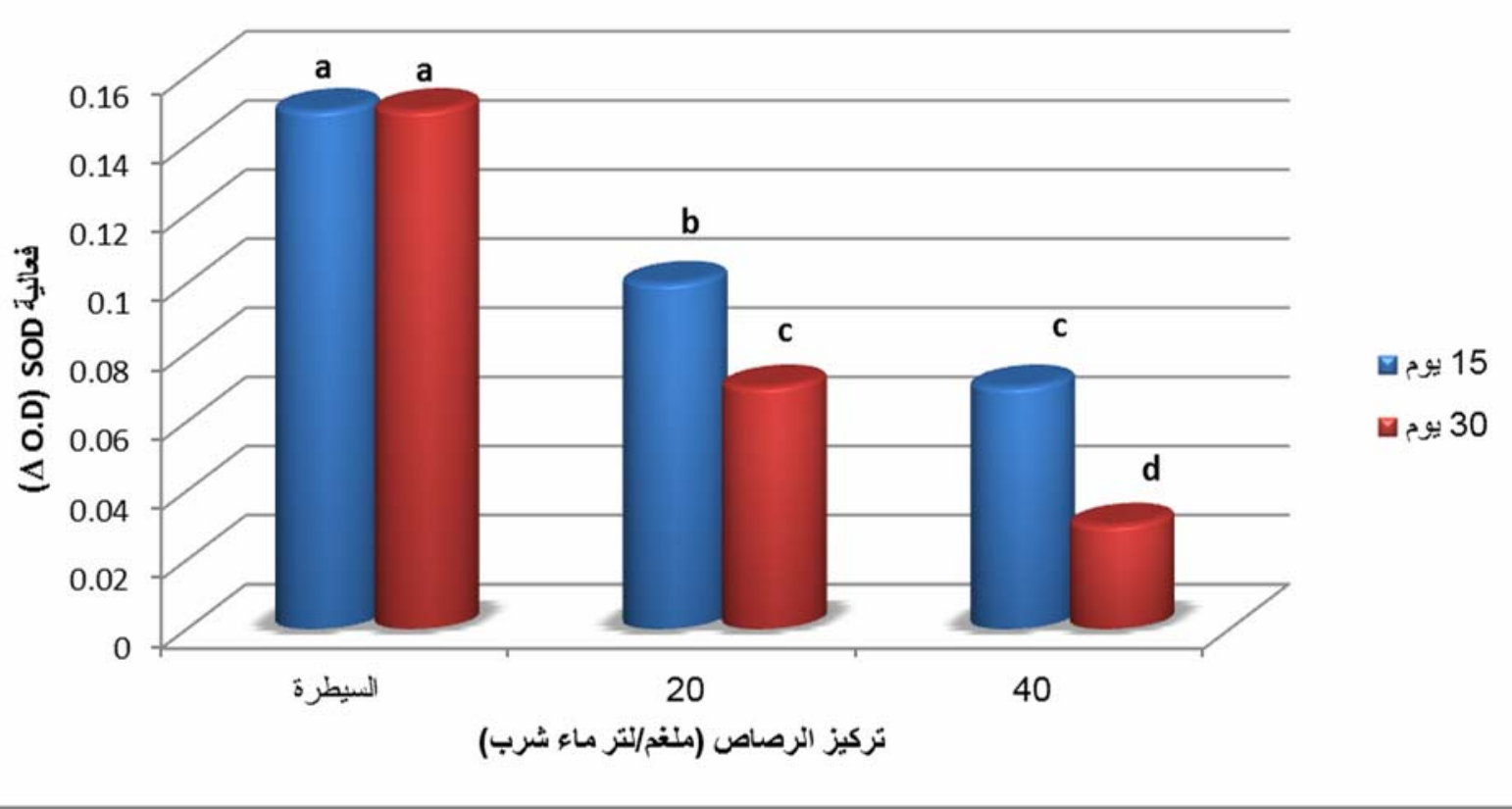

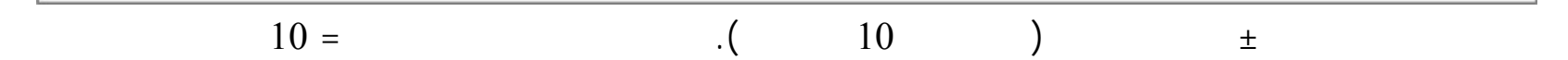

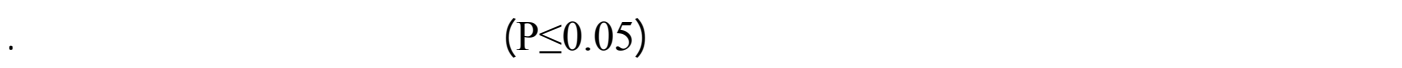

للثكل 5: تأثير الرصاص في فعالية انزيمسوبرر اوكسايد هميوتيز SOD في م صل دم ذك -ور الج -رذان المعلملة بتركيز 20 و40 ملغم رصاص / لترماء للثرب وفلترات مختلفة.

\section{المصادر العربية}

جانكير، منى هسين (2010). درلسة تأثير الكاسميوم في بعض مكونت الدم والمتغيرات الكيموحيوية ل ـذكور

الفئرلن البيض للسويسرية Mus musculus. مجلة تنكريت للعلوم الصرفة، 15(2)، 26-32. جانكير، منف هسن وطه، انتصار غافم (2006) . درلسة تأثير الرصاص في بعض النولهي الحياتية ل ـذكور

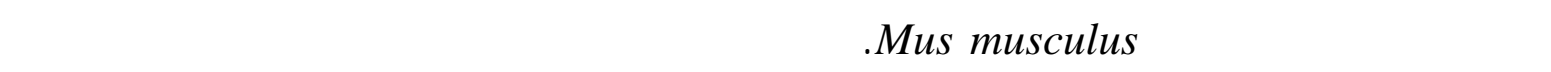
البطري، جلمعة الموصل، الجزء الثاني، 497 -506. الجبوري،سنان نذون (2006). الكفاءة التنلسلية لصغار الجرذلن من لمهات معلملة اثن اءءم ــة الرض اعة بخلات الرصاص: دور فيتلمين E. وسالة ملجستير، كلية الطب البطري، جلمعة الموصل. للسيد، جمل كويس (2000). الملوثلت الكيميائية للبيئة . دار الفجر للنثر والتوزيع، القاهرة، مصرر. عبد الخاق، علاء الدن بيومي (2005).سمية المبيدات والمعان. دار النثر للجلمعلت، الق اهرة، 


\section{المصادر الأجنبية}

Al-Zamely, O.; Al-Nimer, M.; Al-Mushih, R. (2001). Detection the level of peroxynitrite and related with antioxidant status in the serum of patients with acute myocardial infarction .Nat. J. chem., 4,625-637.

ATSDR (Agency for Toxic Substances and Disease Registry) (2005). Tox Guid for lead Pb. Department of Health and Human Servics. Public Health Service, Atlanta, GA.US. $587 \mathrm{p}$.

Bagchi, D.; Bagchi, M.; Hassoun, E.; Etohs, J. (1996). Cadmium induced excretion of urinary lipid metabolities, DNA damage. Glutathione depletion and hepatic lipid peroxidation in sprague dawly rats. Biol. Trace Elem. Res., 52, 143-154.

Basha, B. ; Sovers, I. (1996). Atherosclerosis: an update. Am. Heart. J., 131, 1192-1202.

Beuge, J. A.; Aust, S. D. (1978). "Estimation of Serum Malondialdehyde Level. Methods in Enzymology". Academic press . London, $302 \mathrm{p}$.

Beyer, W.; Imalay, J.; Fridovich, I. (1991). Superoxide dismutase. Prog. Nuclic. Acid. Res. Mol. Biol., 40, 221-253.

Bray, T.; Taylor, G. (1993). Tissue glutathione, nutrition and oxidative stress. Canadian J. Physiol. Pharma., 71, 746-775.

Brown, M.S.; Goldstein, A. (1983). Ann. Rev. Biochem., 25. 233. (cited by Al-Zamely. et al., 2001).

Choudhury, S.; Panda, S. (2004). Induction of oxidative stress and ultra-structural changes in moss Taxithelium nepalense (Schwaegr) both Under lead and arsenic phytotoxicity.Curr. Sci., 87(3), 342-348.

Demir, S.; Yilmaz, M.; Akalin, N.; Aslan, D. (2003). Role of free radicals in peptic ulcer and gastritis. Turk. J. Gastroenterol. 14 (1), 39.

Donaldson, W.; Knowles, S. (1993). Is lead toxicosis a reflection of altered fatty acid composition of membranes ? comparative Biochem. and physiol., 104C, 377-379.

El-Sokkary, G.; Kamel, E.; Reiter, R.(2003). Prophylactic effect of melatonin in reducing lead-induced neurotoxicity in the rat.Cell. Mol. Biol. Lett., 8, 461-470.

Flora, J.; Pande, M.; Kannan, M.; Mehta, A. (2004). Lead induced oxidative stress and its recovery following Co-administration of melatonin or $\mathrm{N}$-acetylcysteine during chelation with succimer in male rats. Cell Mol. Biol. Suppl. 50: OL 543-OL 551. (Abstract).

Freeman, B.M. (1988). Stress and domestic fowl in biochemical research physiological effect of the environment, World's Poultry Sci. J., 44, 41-61.

Gonick, H.; Ding, Y.; Bondy, S.; Ni, Z.; Vaziri, N. (1997). Lead- induced hypertension: Inter play of nitric oxide and reactive oxygen species. Hypertension, 30, 1487-1492.

Gornall, A. C.; Bardawill, C. J.; David, M. M. (1949). Determination of serum proteins by means of the biuret reaction. J. Biol. Chem., 177, 751-766.

Greenberg, M.; Hamilton, R.; Phillips, S.; McCluskey, G. (2003). "Occupational, Industrial and Environmental Toxicology". 2nd edn. By Greenberg, M. USA.

Guemouri, L.; Arthur, Y.; Herbeth, B.; Jeaudel, C.; Gung, G.; Siest, G. (1991). Biology variability of superoxide dismutase, glutathione peroxidase and catalase in blood, Clin. Chem., 37, 24-33. 
Guiihermino, L.; Soares, V.; Carvalho, A.; Lopes, M. (1998). Effect of cadmium and parathion exposure on hematology and blood biochemistry of adult male rats. Environ. Contam. Toxicol, 60, 52-59.

Gurrer, H.; Neal, R.; Yang, p.; Oztenzcan, S.; Ercal, N. (1999). Captopril as an antioxidant in lead-exposed Fischer 344 rats. Human and Exp. Toxicol., 18, 27-32.

Habal, R. (2004). Toxicity, lead. Medicine. 1-24.

Halliwell, B.; Gutteridge, J. (1999). "Free Radical In Biology and Medicine", 3rd edn. Oxford. Oxford University Press, USA, pp.146-163-399-430.

Hermes-Lima, M.; Pereira, B.; Bechara, J. H. (1991). Are free radicals involved in lead poisoning ? Xenobiotica, 21, 1085-1090.

Jankeer, M.; El-Nouri, A. (2009). Histological study of the liver and kidney of albino mice Mus musculus exposed to lead. J. Raf. Sci., 20(2), 42-51.

Jennifer, D.; Findar, D. P. (1982). Albumin by bromocresol green-a case of laboratory conservatism. Clin. Chem., 28(6), 1407-1408.

Kang, J.; Sul, D.; Kang, J.; Nam, S.; Kim, H.; Lee, E. (2004). Effects of lead exposure on they expression of phospholipid hydroperoxidase glutathione peroxidase mRNA in the rat brain. Toxicol. Sci., 82(1), 228-236.

Ketterer, B.; Coles. B.; Meyer D. (1983). The role of glutathione in detoxification. Envir. Health Persp., 49, 59-69.

Kosnett, M. J. (2004). Heavy metal intoxicantion and chelators. In katzung, B. G. "Basic and Clinical Pharmacology". McGraw-Hill, New York, pp. 970-981.

Misra, R.; Smith, G.; Waalkers, M. (1998). Evaluation of the genotoxic potential of cadmium in four different rodent cell lines. Toxicol., 126, 103-114.

Monterio, H.; Abdalla, D.; Augusto, O.; Bechara, E. (1989). Free radical generation during $\delta$-aminolevulinic acid autoxidation : induction by hemoglobin and connections with porphyrinopathies. Archives by Biochem. and Biophys., 271, 206-216.

Monterio, H.; Abdalla, D.; Faljoni-Alario, A.; Bechara, E. (1986). Generation of active oxygen species during coupled autoxidation of oxyhemoglobin and $\delta$ aminolevulinic acid. Biochim. Biophys. Acta., 881, 100-106.

Moussa, S. A.; Bashandy, S. A. (2008). Biophysical and biochemical changes in the blood of rats exposed to lead toxicity . Romanian J. Biophys., 18(2), 123-133.

Mudipalli, A. (2007). Lead hepatotoxicity and potential health effects. Indian J. Med. Res., 126, 518-527.

Newman, D. J.; Price, C. P.(1999). "Renal Function and Nitrogen Metabolism". (cited by Tietz. 1999).

Osumi, J.; Hashimoto, T. (1978). Acyl-CoA oxidase of rat liver: A new enzyme for fatty acid oxidation. Biochem. Biophys. Res. Commun., 83, 479-485.

Plumlee, K. H. (2004). "Metals and Minerals In Clinical Veterinary Toxicology". 1st edn. Mosby. USA. pp. 193-230.

PrasadaRao, P.; Stridhor, M.; Desalu, A. (1983). Effects of oral cadmium administration on mitochondrial enzymes in rat tissues. Arch. Environ. Contam. Toxicol., 12, 293-297.

Quinlan, G.; Halliwell, B.; Moorhouse, C.; Gutteridge, J. (1988). Action of lead(II) and aluminum (III) ions on iron-stimulated lipid peroxidation in liposomes, erythrocytes and rat liver microsomal fraction. Biochemica et Biophysica Acta., 962, 196-200. 
Sandhir, R.; Julka.D.; Gill, K. (1994). Lipoperoxidative damage on lead exposure in rat brain and its implications on membrane bound enzymes. Pharm. and Toxicol., 74, 66-71.

Shalan, M.; Mostafa, M.; Hassouna, S.; Hassab, E.; EL-Rafaie, A. (2005). Amelioration of lead toxicity on rat liver with vitamin $\mathrm{C}$ and silymarin supplements., Toxicol., 206, $1-15$.

Sies, H. (1997). Oxidative stress, oxidants and antioxidants.Exp. Physiol., 82, 291(Abstract).

Singhal, R.; Anderson, M.; Meister, A. (1987).Glutathione, a first line of defense against cadmium toxicity. FASEB J., 1(3), 220-223.

Taki, Y.; Shimahara, Y.; lsselhard, W. (1985).Derangement of hepatic energy metabolism in lead-sensitized endotoxicosis. Eur. Surg. Res., 17, 140-149.

Tang, N,;Enger, M. (1994). $\mathrm{Cd}^{+2}$ induced c-myc mRNA accumulation in NRK-49F cells is blocked by the protein kinase inhibition $\mathrm{H} 7$ butnot HA 1004, Indicating that protein kinase $\mathrm{C}$ is a mediator of the respone. Toxicol., 81, 155-164.

Tietz, N.W. (1999). "Text Book Of Clinical Chemistry". $3^{\text {rd }}$ ed., Burtis, C.A. and Ashwood E.R. (eds) W.B. Saunder compony. London. pp. 1239-1250.

Vaziri, N.; Ding, Y.(2001). Effect of lead on nitric oxide synthase expression in coronary endothelial cells. Hypertension, 37, 223-226.

William, N.S. (1984). Stress and the behavior of domestic fowl., World's Poultry Sci. J., 3, 215-220. 